Научная статья

УДК 373.29

DOI: $10.18101 / 2307-3330-2021-2-46-53$

\title{
ПСИХОЛОГО-ПЕДАГОГИЧЕСКИЕ АСПЕКТЫ ПОДГОТОВКИ ДЕТЕЙ К ШКОЛЕ И АДАПТАЦИИ К ШКОЛЬНОМУ ОБУЧЕНИЮ В ФОРМАТЕ ДИСТАНЦИОННОГО ВЗАИМОДЕЙСТВИЯ
}

\author{
(C) Гармаева Татьяна Владимировна \\ кандидат психологических наук, доцент, \\ Бурятский государственный университет имени Доржи Банзарова \\ Россия, 670000, г. Улан-Удэ, ул. Смолина, 24a \\ gtv_2004@rambler.ru
}

\begin{abstract}
Аннотация. В статье представлен анализ проблем психического развития и обучения детей в условиях дистанционного взаимодействия. Актуализированы пробелы психологической подготовки детей к обучению в школе на примере эмпирических данных диагностики старших дошкольников $(\mathrm{n}=174)$ в период с 2014 по 2021 г. Результаты систематической диагностики свидетельствуют о значимом снижении средних значений показателей психологической подготовки детей к школе, по ряду из которых различия подтверждены статистически (U-критерий Манна-Уитни) в выборках детей 2014 г. $(\mathrm{n}=44)$ и 2021 г. $(\mathrm{n}=41)$ : стеничность, работоспособность, устойчивость и объем внимания, самооценка. В статье вопрос положительных и отрицательных аспектов дистанционного обучения детей рассмотрен сквозь призму преемственности подготовки дошкольников и предстоящей учебной деятельности в начальной школе. В связи с этим были опрошены педагоги дошкольного и начального образования $(\mathrm{n}=184)$, имеющие опыт дистанционного профессионального взаимодействия с детьми.

Ключевые слова: готовность к обучению, старшие дошкольники, педагоги, младшие школьники, дистанционное обучение, волевая сфера, учебная мотивация, произвольность, устойчивость внимания, самооценка, притязания детей, учебные действия.
\end{abstract}

\section{Для цитирования}

Гармаева Т. В. Психолого-педагогические аспекты подготовки детей к школе и адаптации к школьному обучению в формате дистанционного взаимодействия // Вестник Бурятского государственного университета. Образование. Личность. Общество. 2021. № 2. С. 46-53.

Введение. Закон об образовании Российской Федерации предполагает создание условий для самореализации каждого человека, свободное развитие его способностей, включая предоставление права выбора форм получения образования, форм обучения, включая и дистанционные. И актуальность последних связана с современными реалиями жизни: пандемия, условия изоляции и т. д. Хотя в целом как одна из возможных форм обучения дистанционное взаимодействие в ряде случаев является единственно возможной в контексте соблюдения прав маленького гражданина на получение образования. Например, в ситуации проблем со здоровьем, когда возможным становится обучение на расстоянии. Вот только возникает вопрос сохранения, удержания 
T. B. Гармаева. Психолого-педагогические аспекты подготовки детей к школе и адаптации к школьному обучению в формате дистанционного взаимодействия

его эффективности. И не только в контексте результатов обучения, но и в плане полноценности психического развития и социализации детей.

И речь в большей мере идет о детстве в силу того, что тот же подросток, например, уже в большей мере может учиться самостоятельно, у него сформированы все компоненты учебной деятельности - он в целом менее зависит от помощи взрослых. Тогда как о дошкольнике или младшем школьнике мы этого сказать не можем. Поэтому для нас было важно изучить вопрос эффективности дистанционного взаимодействия педагогов с детьми на этапе выхода с детского сада и поступления в школу, иными словами, в контексте преемственности дошкольного и начального образования (психологическая готовность детей к школе, адаптация учащихся к обучению в школе и формирование учебной мотивации на начальных этапах обучения).

На протяжении ряда лет (2014-2021) одно из дошкольных образовательных учреждений г. Улан-Удэ совместно со студентами Педагогического института Бурятского государственного университета (направления подготовки 44.03.02 Психолого-педагогическое образование) проводит диагностику психологической готовности детей к школе. Ее критериями выбраны интеллектуальная готовность (общая осведомленность, опосредованное запоминание, форма мыслительной деятельности, организация деятельности, логическое мышление сформированность операции классификации, логическое мышление, речевое развитие, устойчивость и объем внимания), волевая готовность (работоспособность, усидчивость, волевые качества, стеничность), эмоционально-личностная (уровень притязаний ребенка, самооценка, эмоциональные и личностные особенности, ценностные ориентации), мотивационная (мотивационная готовность к школьному обучению), коммуникативная (характер общения со сверстниками и взрослыми).

Цель. Проследить динамику и проблемные аспекты формирования психологической готовности детей к школе в контексте выявления актуальных проблем дальнейшей адаптации к обучению и становления компонентов учебной деятельности в условиях реализации дистанционного обучающего взаимодействия.

Выборка. В опросе приняли участие 165 педагогов дошкольной ступени образования и 19 учителей начальных классов образовательных организаций Республики Бурятия, работавших в тот период с учащимися первых классов (2020-2021 гг.), а также 174 старших дошкольника в период посещения дошкольной образовательной организации г. Улан-Удэ с 2014 по 2021 г.

Методы исследования. В качестве диагностического инструментария в работе с детьми нами выбран ряд методик: «Общая осведомленность», «Пиктограмма»; «4-й лишний»; «Последовательность событий»; «Изучение объема и устойчивости внимания при помощи простой шифровки»; «7 карточек»; «Мотивационная готовность» (А. Л. Венгер), анкета для воспитателя и наблюдение в ходе обследования. В работе с педагогами был выбран метод опроса с использованием google form.

Результаты. Преимущественно все педагоги ответили, что взаимодействовали с детьми и родителями в период вынужденной изоляции в формате дистанционного профессионального специально организованного общения 
$(93,9$ и 94,7\%). Преимущественно это были различные социальные сети (вайбер, ватсап и т. д. - 94 и 84\%), а также и платформы видео- и аудиосвязи (zoom, skype - 26,7 и 63\%). Как показала практика и данные опроса, чаще к последним прибегали педагоги начальных классов.

На вопрос «Для решения каких преимущественно задач было осуществлено дистанционное взаимодействие с родителями учащихся или воспитанников (законными представителями)?» педагоги начальных классов в большинстве выборов ответили, что для решения организационно-методических вопросов, информационных задач (по 63\%), а также участия детей и родителей в совместных проектах, творческих конкурсах (42\%). Тогда как в дошкольном образовании картина несколько иная - на первом месте стоит участие в проектах, конкурсах $(74,5 \%)$, а уже затем решение организационно-методических вопросов $(44,8 \%)$.

В контексте изучаемой проблемы мы не могли не спросить педагогов детских садов, работавших на момент изоляции с детьми старшего дошкольного возраста, о том, реализовывали ли они дистанционные формы обучающего взаимодействия в контексте подготовки к школьному обучению. На что, к сожалению, $45 \%$ опрошенных педагогов ответили, что такая работа ими не проводилась. Из тех 55\%, что по возможности готовили детей к обучению в школе, наряду с социальными сетями и видео-, аудиоплатформами использовали и различные образовательные программы, и электронные платформы (7,9\%). Среди них отмечены: Padlet, образовательная вкладка сайта Maam, Kahoot, joyteka, развивающие упражнения для детей на Айкюши, Leanis, Навигатор, Педагоги России, детский сад дома, детский сад он-лайн, Lifeworksheets.com, Мерсибо, eSchool, Nsportal, Kids Smart, Инфорурок, Тилли, Рисовалка, фоксворд и т. д.

Как видно из контекста выбранных для работы платформ и ответов педагогов, в большей мере им удалось решить задачи развивающего характера в контексте преемственности дошкольного и начального образования $(58,8 \%)$. При этом больше трудностей, по их мнению, вызвала работа по развитию у детей компетентности в сфере отношений к миру, людям, самому себе $(55,8 \%)$, что в определенной мере, на наш взгляд, обусловлено ситуацией закрытости (изолированности) семей на тот период. На втором место стоят обучающие задачи (66\%), тогда как воспитательного плана задачи набрали $60 \%$.

Отвечая на вопрос «С решением каких задач непрерывного образования детей дошкольного и младшего школьного возраста было больше всего трудностей?», большинство опрошенных ответили - с развитием компетентности в сфере отношений к миру, людям, самому себе, включением детей в социальные контакты (87\%). В целом из-за сужения круга социальных контактов детей на тот момент. Значимым для нас является такой ответ на вопрос, как «обеспечение эмоционального благополучия каждого ребенка». Данная проблема неоднократно была озвучена представителями разных профессий, связанных с социальным взаимодействием (педагогами, психологами, социологами). Особо остро этот вопрос стоит перед семейными психологами и консультантами, так как в период изоляции дети и родители были закрыты в едином пространстве, решая при этом задачи обучения, организации домашнего 
T. B. Гармаева. Психолого-педагогические аспекты подготовки детей к школе и адаптации к школьному обучению в формате дистанционного взаимодействия

быта и т. д. Это так или иначе становилось фактором роста психологического напряжения. При этом именно на эмоциональную сторону психического развития, как показали результаты опроса, обращалось внимание не в самую первую очередь как родителями, так и педагогами (42,2\%). Абсолютные значения (100\%) получила познавательная сфера. Наряду с эмоциональной составляющей психического развития детей в этом плане также «запавшими» оказались волевая и личностная сферы (соответственно 18 и 26,5\%), что указывает на необходимость реализации соответствующего психологопедагогического сопровождения развития детей в контексте психоэмоционального благополучия и гармоничности развития.

Если посмотреть на оценивание педагогами по пятибалльной системе работы, которую они смогли реализовать на тот период, то развитие произвольности в целом оценили на 3-4 балла, тогда как все остальные получили по 4 балла преимущественно: стимулирование познавательной активности, стимулирование творческого самовыражения, развитие познавательных процессов, стимулирование игровой активности. При этом следует отметить, что проблема формирования произвольности как одного из критериев волевой сферы психического развития ребенка нашла отражение в практике работы с учащимися начальных классов, также как проблема формирования необходимых для учебной деятельности волевых универсальных учебных действий в младшем школьном возрасте из-за трудностей осуществления дистанционного обучения детей или в целом организации учебного процесса, как и в старшем дошкольном возрасте, когда речь идет о волевой подготовке ребенка к школе. Связано это в данном случае с тем, что дети, обучающиеся во втором классе, часть подготовительной к школе группы учились дистанционно, в условиях домашнего обучения, при этом у родителей не во всех случаях получалось качественно организовать ребенку рабочее место, учебный процесс, правила обучающего взаимодействия по различным причинам.

В целом мы согласны с устоявшимся мнением о том, что готовность ребенка к школе является комплексным явлением. Однако, на наш взгляд, не в полной мере можно согласиться с тем, что «базовой его составляющей является хорошо развитая познавательная мотивация, а также мотивация учения и умение учиться» [1, с. 19]. Подобное мнение высказывают и Е. В. Гончарова, И. И. Левашова, говоря о значимости формирования познавательных, практических, организационно-ценностных умений и учебно значимых качеств личности, составляющих учебно-познавательную компетентность [2].

Тем самым умаляется роль развития волевой сферы старших дошкольников, из-за чего в будущем будет обусловлен успех формирования некоторых элементов учебной деятельности. Более того, нами было получено эмпирическое подтверждение актуальности проблемы формирования волевой сферы у современных дошкольников при анализе результатов проведенной нами диагностики детей.

Общая картина формирования компонентов психологической готовности детей к обучению в школе наглядно отражена в средних общих баллах в таблице 1. Как видно из таблицы, в целом за эти годы существенно снизился общий уровень подготовки детей к обучению в школе по параметрам, отно- 
сящимся к волевой сфере (работоспособность, волевые качества, стеничность), и связанной с ней устойчивости внимания. Также определенной оценки требуют уровень притязаний детей и самооценка как критерии личностной готовности к школе, к предстоящей учебной деятельности. Данные результаты в последующем становятся одними из значимых факторов формирования элементов учебной деятельности и необходимых универсальных учебных действий, что затрудняет понимание учебных задач, формирование самоконтроля, отрицательно скажется на психоэмоциональном благополучии детей, обусловит проявление учебной тревожности.

Таблица 1

Динамика сформированности компонентов психологической готовности детей к школе (средние баллы)

\begin{tabular}{|l|l|l|l|l|l|}
\hline \multirow{2}{*}{ Критерии } & \multicolumn{5}{c|}{ Год } \\
\cline { 2 - 7 } & 2014 & 2015 & 2016 & 2019 & 2021 \\
\hline Общая осведомленность & 2,7 & 2,3 & 2,9 & 2,7 & 2,4 \\
\hline Опосредованное запоминание & 2,1 & 2,0 & 1,9 & 1,8 & 2,1 \\
\hline Форма мыслительной деятельности & 1,9 & 2,0 & 2,4 & 2,0 & 2,0 \\
\hline Организация деятельности & 2,3 & 1,8 & 2,0 & 2,2 & 2,0 \\
\hline $\begin{array}{l}\text { Сформированность операции классифи- } \\
\text { кации }\end{array}$ & 2,6 & 2,7 & 2,7 & 2,6 & 2,4 \\
\hline Речевое развитие & & & & & \\
\hline Устойчивость и объем внимания & 2,5 & 2,4 & 2,3 & 2,7 & 2,4 \\
\hline Работоспособность & $\mathbf{2 , 7}$ & $\mathbf{2 , 4}$ & $\mathbf{2 , 3}$ & $\mathbf{2 , 2}$ & $\mathbf{1 , 7}$ \\
\hline Волевые качества & $\mathbf{2 , 6}$ & $\mathbf{2 , 5}$ & $\mathbf{2 , 5}$ & $\mathbf{2 , 5}$ & $\mathbf{2 , 0}$ \\
\hline Стеничность & $\mathbf{2 , 6}$ & $\mathbf{2 , 3}$ & $\mathbf{2 , 5}$ & $\mathbf{2 , 6}$ & $\mathbf{2 , 2}$ \\
\hline Уровень притязаний & $\mathbf{2 , 5}$ & $\mathbf{2 , 3}$ & $\mathbf{2 , 4}$ & $\mathbf{2 , 6}$ & $\mathbf{2 , 0}$ \\
\hline Самооценка & $\mathbf{2 , 0}$ & $\mathbf{1 , 8}$ & $\mathbf{2 , 0}$ & $\mathbf{2 , 1}$ & $\mathbf{1 , 6}$ \\
\hline Эмоциональная регуляция & $\mathbf{2 , 3}$ & $\mathbf{1 , 9}$ & $\mathbf{2 , 2}$ & $\mathbf{2 , 2}$ & $\mathbf{1 , 8}$ \\
\hline Мотивационная сфера & 2,6 & 2,4 & 2,4 & 2,5 & 2,2 \\
\hline Характер общения со сверстниками & 2,5 & 2,1 & 2,4 & 2,4 & 2,0 \\
\hline Характер общения со взрослыми & 2,5 & 2,7 & 2,6 & 2,3 & 2,5 \\
\hline & 2,6 & 2,4 & 2,7 & 2,5 & 2,4 \\
\hline
\end{tabular}

Более того, данные таблицы 1 определили необходимость проведения сравнительного анализа полученных результатов диагностики старших дошкольников 2014 г. и 2021 г. Работа была проведена с помощью метода МаннаУитни. Число обследованных детей в 2014 г. составило 44 чел., в 2021 г. - 41. Так, нами были выявлены статистически достоверные значимые различия в уровнях сформированности у детей на момент обследования устойчивости и объема внимания (Uэмп=468), работоспособность (Uэмп=622), стеничность $($ Uэмп $=579)$ и самооценка (Uэмп=600,5). В зону неопределенности попали результаты по таким критериям, как «волевые качества» (Uэмп=650), уровень притязаний $($ Uэмп=696,5) и эмоциональная регуляция (Uэмп=644). На наш взгляд, среди возможных факторов, определивших подобную картину в 2021 г., стала проведенная работа с детьми в он-лайн формате, в том числе по причине одного из ключевых минусов подобного обучающего взаимодействия - «отсутствия 
T. B. Гармаева. Психолого-педагогические аспекты подготовки детей к школе и адаптации к школьному обучению в формате дистанционного взаимодействия

возможности общения ребенка со сверстниками» [3, с. 59]. Именно через непосредственное взаимодействие со сверстниками дошкольник не только узнает новое и интересное, но и с большим успехом социализируется. При этом социализация понимается не только в контексте расширения социальных ролей и т. д., но и усвоения норм социокультурного взаимодействия, сопряженного с необходимостью соблюдения определенных правил, формирования волевых качеств и уровня притязаний, а также получения информации для самооценивания и т. д.

В этом случае следует вновь обратиться к проведенному опросу педагогов начальных классов в связи с тем, что здесь мы также в большей мере сталкиваемся с вопросом произвольности и саморегуляции. Об этом свидетельствуют ответы на вопрос «С какими трудностями в большей мере пришлось столкнуться при реализации он-лайн обучения детей (кроме технических)». Это проблемы с контролем и самоконтролем выполнения заданий (63\%), что в целом характерно для детей младшего школьного возраста, тем более учащихся первых классов. Необходимо отметить, что в этом случае проблемы дисциплины не столь выражены (всего 15,8\%), видимо, по причине непосредственной помощи родителей, которым приходилось находиться рядом с ребенком во время уроков и выполнения домашних заданий. Об этом свидетельствуют и отдельные ответы педагогов: «неумение работать без контроля взрослых» и т. п. Также указывается в различных исследованиях проблем дистанционного обучения детей наряду с необходимостью защиты здоровья детей по причине их увлеченностью гаджетами, эмоциональной неустойчивости и т. д.

При оценивании по пятибалльной системе проведенной работы опрошенными педагогами отмечен пробел в развитии произвольности и формировании учебной мотивации (преимущественно 3 балла). Тогда как, например, стимулирование коммуникативной активности, творческого самовыражения, развитие познавательных процессов они оценили на 4 балла.

Выводы. Сегодня, несмотря на то, что педагогами проводится работа по устранению недостатков дистанционного обучения как в период дошкольного образования, так и обучения в первом, втором классах, педагоги-психологи столкнулись с огромным полем требующих решения проблем психического развития детей. В частности, проблем, касающихся волевой сферы и эмоциональноличностного развития. Обусловлено это тем, что педагоги преимущественно используют педагогические методы воздействия: пересматривают систему используемых методов, средств обучения, беседуют с родителями и т. д. Проблема заключается, на наш взгляд, в том, что если педагоги так или иначе решают методические вопросы обучающего взаимодействия с детьми, то необходимо это грамотно и психологически тонко донести до родителей. Знакомить не только с методиками обучения, но и в первую очередь с психологическими аспектами обучения. Поскольку родителям сложно преодолевать свою позицию, отмечаются множество конфликтов в детско-родительском взаимодействии, эмоциональная неустойчивость, рост тревоги у детей и, соответственно, отрицательное отношение к учебной деятельности в целом.

И в первую очередь, по результатам диагностики, важно обратить внимание на волевую сферу, психоэмоциональное состояние и личностное развитие детей. Работа по психолого-педагогическому сопровождению психического раз- 
вития детей должна быть систематической с использованием богатого инструментария развивающей, профилактической и коррекционной работы. Важно понимать, что инструментарий необходимо пересматривать, менять, адаптировать к условиям дистанционного профессионального взаимодействия с учетом особенностей развития и социализации современных детей.

\section{Лuтература}

1. Белошистая А. В. Психологическое обоснование необходимости предшкольной подготовки ребенка // Психология обучения. 2009. № 9. С. 19-23. URL: https://elibrary.ru/download/elibrary_12839021_96765572.pdf (дата обращения: 10.11.2021). Текст: электронный.

2. Гончарова Е. В., Левашова И. И. Формирование учебно-познавательной компетенции дошкольников как основы подготовки к учебной деятельности на этапе предшкольного образования // Вестник Нижневартовского государственного гуманитарного университета. 2010. № 1. C. 8-12. URL: https://elibrary.ru/download/ elibrary_17725062_20249917.pdf (дата обращения: 10.11.2021). Текст: электронный.

3. Елистратова Е. Б. Проблемы дистанционного обучения дошкольников // Дошкольное образование в современном меняющемся мире: теория и практика: материалы VI Международной научно-практической конференции: в 2 ч. (Чита, 26-27 ноября 2020). Чита: Изд-во Забайкальского гос. ун-та, 2020. С. 57-60. Текст: непосредственный.

Статья поступила в редакиию 05.06.2021; одобрена после рецензирования 05.07.2021; принята к публикациии 29.11.2021.

\section{PSYCHOLOGICAL AND PEDAGOGICAL ASPECTS OF CHILDREN'S SCHOOL READINESS AND ADAPTATION TO DISTANCE LEARNING}

Tatyana V. Garmaeva

Cand. Sci. (Psychology), A/Prof., Dorzhi Banzarov Buryat State University 24a Smolina St., Ulan-Ude 670000, Russia gtv_2004@rambler.ru

Abstract. The article presents an analysis of the problems of psychological development and education of children in the conditions of distance learning. We have analyzed the gaps in the psychological readiness of children to school based on the empirical data from the diagnostics of over-fives $(n=174)$ in the period from 2014 to 2021. The results of systematic diagnostics show a significant decrease in the average values of a number of indicators of psychological readiness of children to school. For some of indicators we have statistically confirmed the differences (MannWhitney $U$ test) in the samples of children in $2014(n=44)$ and $2021(n=41)$ : sthenicity, attention span, self-attitude. The article considers the positive and negative aspects of distance learning through the prism of the continuity of preschoolers' training and the upcoming educational activity in primary school. In view of this, we interviewed preschool and primary school teachers $(n=184)$, who have experience of distant interaction with children.

Keywords: school readiness, over-fives, teachers, elementary school children, distance learning, volition, learning motivation, lack of motivation, attention span, selfattitude, academic aspiration, learning activities. 
T. В. Гармаева. Психолого-педагогические аспекты подготовки детей к школе и адаптации к школьному обучению в формате дистанционного взаимодействия

For citation

Garmaeva T. V. Psychological and Pedagogical Aspects of Children’s School Readiness and Adaptation to Distance Learning. Education. Person. Society. 2021; 2: 46-53 (In Russ.).

The article was submitted 05.06.2021; approved after reviewing 05.07.2021; accepted for publication 29.11.2021. 